\title{
TECHNOLOGY TRANSFER AS INNOVATION DRIVER FOR GROWTH
}

\author{
Tsvetana Stoyanova ${ }^{6}$ \\ Nikolay Sterev ${ }^{7}$
}

https://doi.org/10.31410/itema.2018.13

\begin{abstract}
Information is essential in the daily management process at any business. It focuses on knowledge, know-how, skills and experience and is one of the main drivers of the innovation process. Companies that devote significant resources to research the market and to develop new products, processes and/or technologies are those ones that are the largest technology licensors. In the terms of Industry 4.0 there is a shift from labor-intensive and capital-intensive industries to knowledge-based and technology-based economies. As competition grows and covers not only national but also international markets, technology emerges as an important business driver in red oceans of competitive battleship. To support a long-term growth goals, new technologies and their intellectual properties could become an object of a marketing. In this case we are talking about technology transfer.

In this paper, the subject of research will be the analysis of different ways of managing the technology transfer focusing on transfer on commercial basis. The core of the analysis is to find out the exact dependence between density of technology transfer and innovation based business success that dependence is typical for Bulgaria and Bulgarian companies. In conclusion the reference to the competitiveness level of Bulgarian economy and the calculated innovation based dependence will be presented. That will allow to state our recommendations to the Bulgarian mangers how to increase business growth and competitiveness based on the technology transfer.
\end{abstract}

Keywords: Technology transfer, innovation business, industrial growth

\section{INTRODUCTION}

I nnovations, undoubtedly are appointed as a key factor for the competitiveness on national and business level. As the EC set: "Industry is the engine of innovation" [1], the innovations are the hearth of the EU Innovation policy and Innovation Strategy 2020. Furthermore, the main instrument for the implementation of ongoing Strategy 2020 (and up-coming EU Strategy 2030) is EU initiative Innovation Union [1] - [2].

There are many definitions for the innovations. However, the key words of innovations are: to be new (idea; product; technology; business model); to be successful (practically implemented; has potential for growth; added new value); to be smart (to lead growth; to expand markets; to develop competition). They are based on the fundamental researches as a first leg of innovation value chain [3]. In addition, a fully operated research excellence is needed to boost smart growth and competitiveness of the EU, EU member states and EU businesses [1].

European research network explores the opportunities to establish stable innovation environment for fostering a common work on projects that support digitalization (Industry 4.0

\footnotetext{
${ }^{6}$ Department of Management, UNWE-Sofia, Bulgaria

${ }^{7}$ Industrial Business Department, UNWE-Sofia, Bulgaria
} 
and Industry 5.0) [4] and that promote resource efficiency and circular (regenerative) economy. The key word is open (shared) information: knowledge and know-how transfer; skills and experience leverage, as main drivers for successfully smart innovation process.

\section{INNOVATIONS AND TECHNOLOGY TRANSFER}

(Innovative) Companies that devote significant resources to research the market and to develop new products, processes and/or technologies are those ones that are the largest technology licensors. In the terms of ongoing stable growing Industry 4.0, and up-coming Industry 5.0, there is a shift from labor-intensive and capital-intensive industries to knowledge-based and technology-based economies. As competition grows and covers not only national but also international markets, technology emerges as an important business driver in red oceans of competitive battleship.

The best excellence business practices are based on innovations development and its successful market introduction and commercialization. In emerging markets such as electronics, biotechnology and nanotechnology (the Industry 5.0 sectors), the introduction of new products based on new technologies is essential. Even for traditional industries such as food production, textile and clothing, new technologies are needed to maintain their smart grow.

To support a long-term growth goals, new technologies and their intellectual properties could become an object of a marketing. In this case we are talking about technology transfer. Wahab, Rose and Osman [5] presented different approaches to defining the "Technology transfer":

- as a process by which ideas and concepts are moved from the laboratory to marketplace (see [6] - [7]);

- $\quad$ as a process by which products and technologies are broaden from developed to less technologically developed countries (see [8]);

- $\quad$ as a process by which inventions are transferred to secondary users (see [9]).

The information and know-how transfer could be based on couple of mechanisms depending on the payment for transfer: commercial and non-commercial.

The main forms of technology transfer on a commercial basis are: license and know-how contracts, franchising, leasing, foreign direct investment etc. Non-commercial transfer is found as element of development of the innovative business environment and could be mediate through: common project research; Conference presentation; Paper publication; Informal discussion via Social networks.

Technological transfer could be found in two forms: vertical and horizontal. Vertical transfer is found from research via development and production to distribution in well-developed countries and from distribution via production and development to research in developing countries. The horizontal transfer could be found as new product/technology information exchange between two business organizations within one country or between two countries (see Figure 1) [10]. 
Figure 1. Technology transfer building

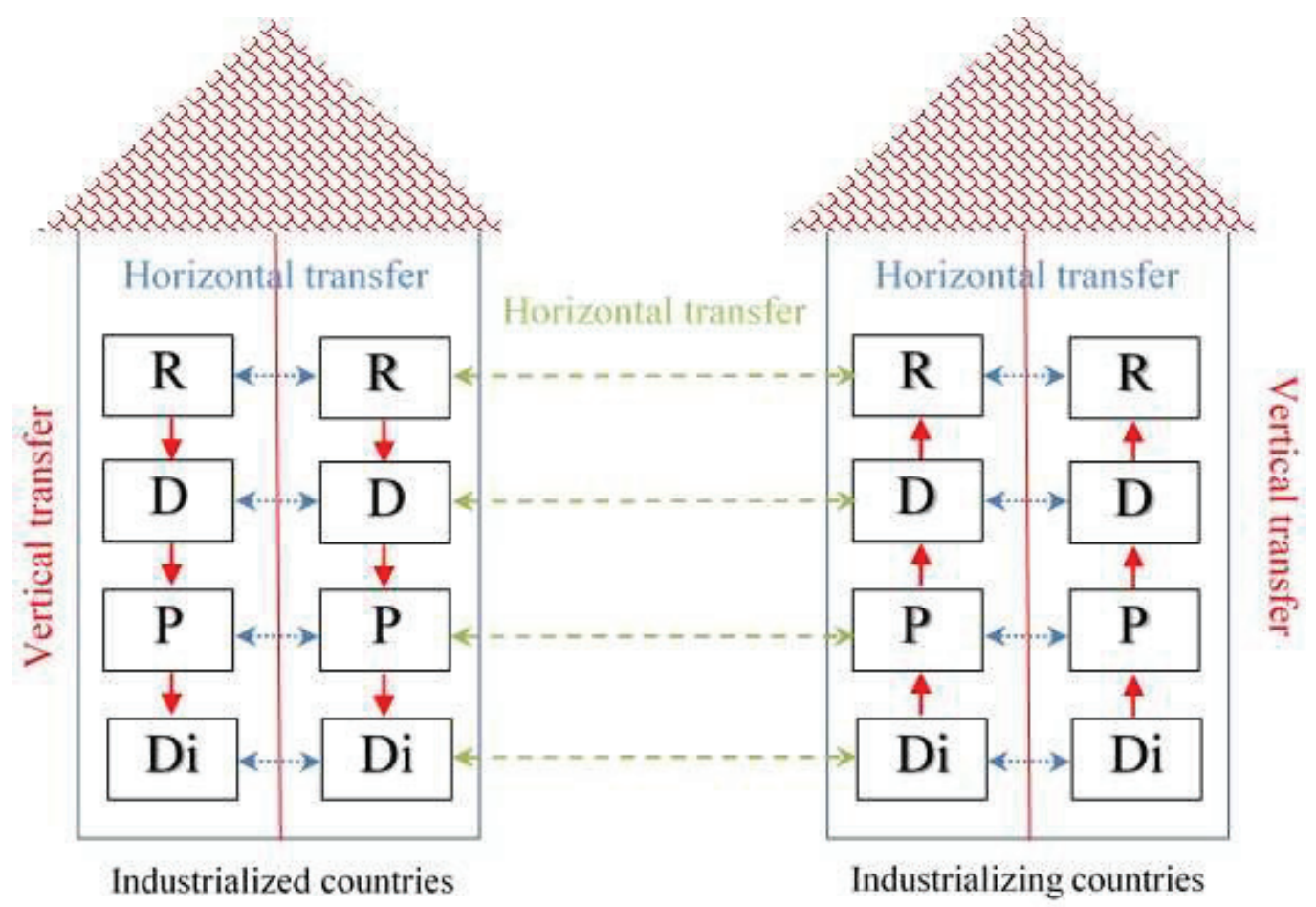

The main forms of commercial technology transfer (TT) are (see [11] - [14]):

- License: acquisition of technology know-how against a deal payment of the Intellectual Property (IP) rights.

- Patents: payee that is owner of exclusive rights with a patent for invention transfers those rights to another person or business organization (payer).

- Contract of sale: provides payment for a design, construction and assistance agreement for the initial technology to the technology know-how supplier.

- Joint-venture Spin-off: two or more companies merge their research resources and technology experience in the research and development, production or distribution of innovative products or technologies.

- Delivery of technology to industry: transferor purchasing new machinery and equipment with a high degree of technical complexity from technology transferee to produce new or high technology products and services.

- Joint research projects: two or more companies merge their research and development activities with research institutes or universities.

Nevertheless, the diversity of TT mechanisms and transfer mediums could not guarantee the technology transfer success. Nevertheless, the innovation success could be found by technology transfer policy based on the next 4 principles [15]:

- Introducing expert score-card for selection of the partner(s);

- Establishing long-term engagement of the partner(s);

- Accepting marketing leadership and marketing drive management to the joint venture;

- Maintaining the technology leadership and future technology innovation control.

\section{BULGARIAN PRACTICE FOR INNOVATION ENCOURAGING}

At the present stage of the national economic development, most of Bulgarian companies are implementing a low-priced strategy. As the greatest number of companies use obsolete 
technologies, methods and management approaches that lead them to direct refusal to innovate it is a challenging opportunity for introduction innovative technologies and business models in Bulgarian economy. Thus, accepting the innovation approach could be a small step for the Bulgarian entities, but it will be a great step for the competitiveness of the Bulgarian economy.

By the industrial growth policy, Bulgarian government could help the economy for enlarging the numbers of the innovative Bulgarian business than the figures from $2016^{\text {th }}$. (Table 1) [16]

Table 1. Share of the Bulgarian innovative business in 2016, \%

\begin{tabular}{|l|r|r|r|}
\hline & $\begin{array}{c}\text { Innovative } \\
\text { enterprises } \\
\text { (total) }\end{array}$ & $\begin{array}{c}\text { Technology } \\
\text { innovative } \\
\text { enterprises }\end{array}$ & $\begin{array}{c}\text { Non--technolo } \\
\text { innovative } \\
\text { enterprises }\end{array}$ \\
\hline TOTAL, incl.: & $\mathbf{2 7 . 2}$ & $\mathbf{1 9 . 8}$ & $\mathbf{1 7 . 3}$ \\
\hline Industry (codes B, C, D and E) & 31.6 & 24.9 & 1 \\
\hline Services (codes H, J and K) & 22.1 & 14.1 & 1 \\
\hline $10-49$ employees & 20.5 & 15.2 & 6 \\
\hline $50-249$ employees & 44.3 & 32.9 & 1 \\
\hline above 250 employees & 81.9 & 50.6 & \\
\hline Remarks: ${ }^{\text {a. }}$ technology innovation includes: product and process innovations \\
b. non-technology innovation includes: organizational and marketing innovations
\end{tabular}

According to the Table 1, 19.8\% of all legal entities in Bulgaria have introduce technology innovation (product and/or process innovations), 17.3\% - non-technology innovations (organizational and marketing innovations), and $4.95 \%$ - both.

More deeply, the Bulgarian National Statistical Office (NSI) explores the type of the product innovations. Thus, $12.8 \%$ of companies have introduced new products or services (product innovations) in 2016 that reports $24.4 \%$ of the total turnover of the Bulgarian business. $65.2 \%$ - established a new product decision for current markets, as $81.6 \%$ - just start producing new product for them, but not new for the markets. The importance of these product innovations could be given by the next figures: $6.0 \%$ of turnover is reported as result of new for the business innovative products, $2.7 \%$ - from new products for the industry and 3.3\% - from new products for the enterprises.

In addition, $11.6 \%$ of total companies have introduced new processes (process innovations) in 2016, as 8.1\% - new main process methods and approaches, $6.4 \%$ - new supporting process methods and approaches, and 3.4\% - just amended their supply chain and/or distribution process methods and approaches.

Less number of enterprises used non-technology innovations in 2016. 12.6\% introduce new approaches to workplaces and employees (organizational innovations), including 9.5\% with new internship methods and $8.9 \%$ with new competencies methods.

Just $12.0 \%$ of all companies have developed new marketing strategies and/or new marketing instruments (marketing innovations), as $8.4 \%$ - new advertising methods and instruments, and $5.9 \%$ - new pricing methods and instruments. 
Nevertheless, we could find a slight improvement of the Bulgarian innovations between 2014 and 2016 (Figure 2) [16].

Figure 2. Share of the Bulgarian innovative business in 2014-2016, \%

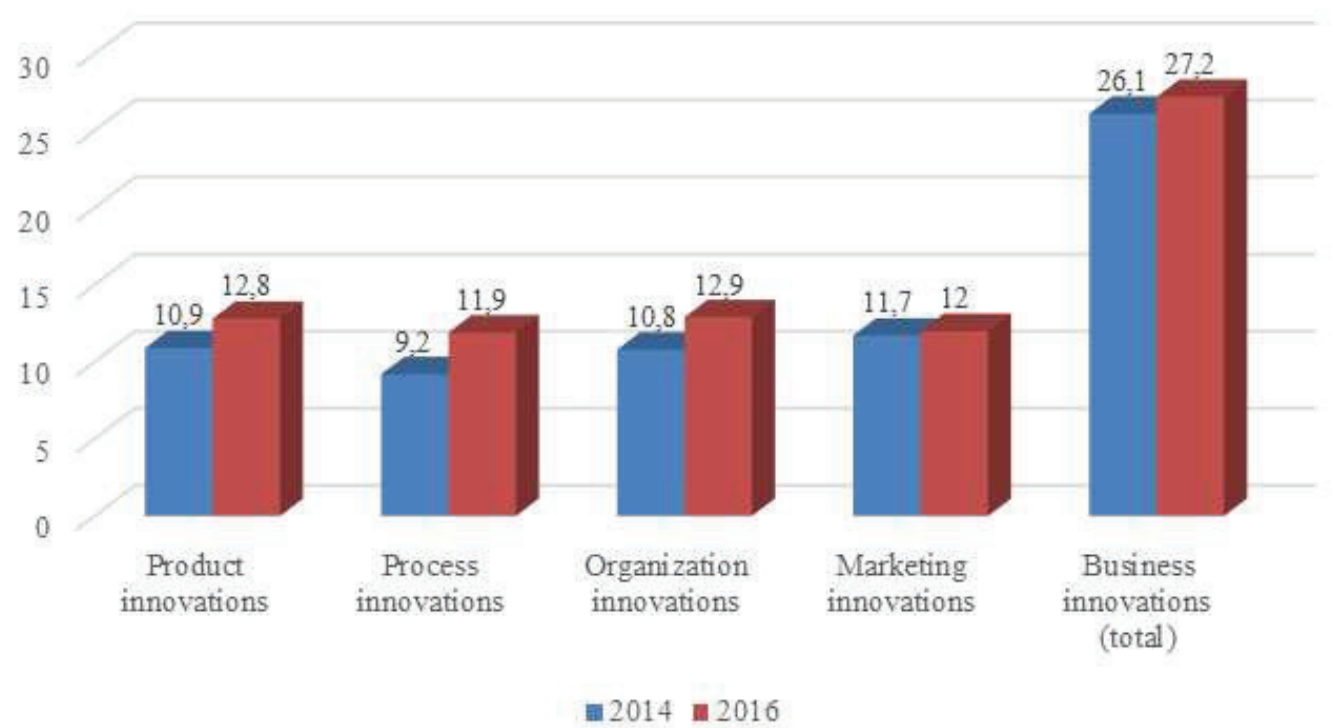

The reported innovations basically are developed without any cooperation. Not more than $20 \%$ of total business innovations are result of business cooperation. Respectively, as the bigger is the business than the greater number of innovations are done in cooperation. Thus, $17.8 \%$ of small enterprises combine in innovations as this figure is double: $35.8 \%$ of holding cooperate for innovating. (Table 2) [16]

Table 2. Share of the Bulgarian innovation business done in combination and cooperation in $2016, \%$

\begin{tabular}{|c|c|}
\hline TOTAL, incl.: & $\mathbf{2 0 1 6}$ \\
\hline Industry (codes B, C, D and E) & $\mathbf{2 0 . 9}$ \\
\hline Services (codes H, J and K) & 17.4 \\
\hline $10-49$ employees & 28.0 \\
\hline $50-249$ employees & 17.8 \\
\hline above 250 employees & 22.6 \\
\hline
\end{tabular}

\section{CONCLUSIONS}

Keeping innovation potential at a high level of the technology and non-technology innovations, as well as the establishing fast growing products and/or process innovations are some of the main kay factors for sustainable and competitive development of the Bulgarian economy and Bulgarian industry as well. Some of the principles that have to be introduced by the Bulgarian innovative business includes the next ones: 
- Establishing employees' competencies to react to changes in the competitive environment, and to uses open strategic opportunities window through various forms of technology transfer;

- Establishing innovative business culture that explores employees' attitudes for knowledge acquisition and knowledge based development;

- Establish open networks based on national and international innovation networks, not just following supply chain added value, but based on combination and cooperation with other competitors and/or universities and research centers.

The main challenge to innovation business' development is that Bulgarian enterprises still have no business culture that is needed for the sharing economy. This is obstacle that prevents implementing common projects for introducing new production processes and new industry products. In addition, the orientation to the cooperation inside the existing supply chain networks declines the national potential for competitiveness and growth.

Exploiting the given opportunities and challenges is a priority of the Bulgarian National Strategy for Competitiveness and for the Industrial Renaissance 2020 and 2030 as well.

\section{REFERENCES}

[1] EC, https://ec.europa.eu/

[2] Zhelev P. (2015), Analysis of the Competitiveness of Bulgaria's regions after the European Union Accession, Trakia Journal of Sciences, 13 (1), 2015, p.60-67

[3] NCP Academy (2016), http://www.ncpacademy.eu/wpcontent/uploads/2016/12/20161018_Presentation_Innovation_PH.pdf

[4] Sterev N., V. Kisimov, T.Stoyanova, V.Andonov (2018), Multidimencial Framework for Crosscorporate Business Social Network (BSN), 11th IADIS International Conference on Information Systems (IS 2018)

[5] Wahab S.A., R.C. Rose, S.I.W. Osman (2012). Defining the concepts of technology and technology transfer: a literature analysis, International Business Research, 5 (1) (2012), pp. 61-71

[6] Phillips, R. (2002). Technology Business Incubators: How Effective Is Technology Transfer Mechanisms? Technology in Society, 24 (3), 299-316. http://dx.doi.org/10.1016/S0160-791X(02)00010-6

[7] Blagoev D. M. (2011), Measuring of Innovation Activities in Bulgarian Industry and Reaching the Parameters of the Strategy 2020 of EU, 7th Research/Expert Conference with International Participations "QUALITY 2011“, http://www.quality.unze.ba/zbornici/QUALITY\%202011/062-Q11-028.pdf

[8] William, F., \& Gibson, D. V. (1990). Technology Transfer: A Communication Perspective. Sage: Beverly Hills, CA.

[9] Gibson, D. V., \& Rogers, E. M. (1994). R\&D Collaboration on Trial: The Microelectronics and Computer Technology Corporation. Harvard Business Press.

[10] Steenhuis Harm-Jan, Sirp J. de Boer (2002), Differentiating between types of technology transfer: the Technology Building, International Journal of Technology Transfer and Commercialisation 1(1/2), January 2002

[11] Arenas, Juan Jesus, and Domingo González (2018). Technology Transfer Models and Elements in the University-Industry Collaboration, Adm. Sci. 2018, 8, 19; doi:10.3390/admsci8020019

[12] Mechanism of Technology Transfer and its Effectiveness, http://shodhganga.inflibnet.ac.in/bitstream/10603/14849/13/14_chapter\%206.pdf 
[13] Sagar Pagar et al. (2014), Review article on technology transfer, International Journal of Pure \& Applied Bioscience, 2 (3): 145-153 (2014)

[14] Zhelev P. (2014), International Technology Transfer to Bulgaria after its European Union Accession, Economic Alternatives Journal, 3/2014, p.83-94

[15] Ramanathan K, An Overview of Technology Transfer and Technology Transfer Models, http://tto.boun.edu.tr/files/1383812118 An\%20overview\%20of\%20TT\%20and\%20TT\% 20Models.pdf

[16] NSI, http://www.nsi.bg/bg/ 